\title{
Optimal flow rates and well locations for soil vapor extraction design
}

\author{
Charles S. Sawyer *, Madhavi Kamakoti \\ Department of Civil and Environmental Engineering, U-37, University of Connecticut, Storrs, CT 06269, USA
}

Received 24 December 1996; revised 7 October 1997; accepted 7 October 1997

\begin{abstract}
A mixed-integer programming model to determine the optimum number of wells, their locations and pumping rates for soil vapor extraction (SVE) is developed by coupling an air flow simulation model (AIR3D) to the GAMS optimization software. The model was tested for sensitivity of the vertical discretization of the domain, the number of potential well locations, the number of constraints, and the screen length of the wells. It was shown that these variables affected the optimal solution. It was also shown that the installation costs of the wells in the model influenced the optimal design. This was demonstrated by comparing the results of the mixed-integer programming model to a linear programming model in which the installation costs of the wells were neglected. The mixed-integer programming model could be useful in the design process in cases of short remediation times when the installation costs of wells could be significant. Numerous test cases with results are presented to demonstrate the applicability and usefulness of the model. (C) 1998 Elsevier Science B.V. All rights reserved.
\end{abstract}

Keywords: Optimal flow rates; Wells; Soil vapor extraction

\section{Introduction}

The use of soil vapor extraction (SVE) as a remediation technology for the unsaturated zone is increasing and can be more efficient and cost-effective in comparison to remedial strategies like excavation or pump-and-treat (Johnson et al., 1990). In SVE, air is introduced into the unsaturated zone to increase the volatilization of the contaminant and a vacuum is created by extracting the air and contaminant vapor using extraction well(s). The rate of vapor removal depends on the contaminant's volatility, its sorptive

\footnotetext{
${ }^{*}$ Corresponding author.
} 
capacity on to the soil, the initial distribution of the contaminant, the distribution of the air flow, hydraulic properties of the soil, the soil moisture content, etc. SVE success depends greatly on the contaminant volatility which is a phase partitioning process usually described by Raoult's equilibrium law in most practical applications. This equilibrium law is useful in situations were the volatilization is relatively large compared to the rate of physical transport through the unsaturated zone. However, as the lighter contaminant fractions are removed, SVE removal efficiency declines due to other factors such as diffusion controlled mass transfer of contaminants. In this work, it is assumed that the moisture content and the sorptive capacity of the contaminant on to the soil are negligible, that the equilibrium law holds and advection transport governs the movement of the contaminant vapor to the extraction wells. In this case, the distribution of the contaminants would be relatively homogeneous and much of the air would sweep through the bulk of the contaminant. With these assumptions, the gas flow field could be used to help in deciding cost effective SVE design.

If the extent of contamination and the geologic characteristics of the site are known, then some of the important components of the design are the number of wells, the placement of the wells and the pumping rate of each well. Limited quantitative design criteria and guidelines have appeared in the literature (Rathfelder et al., 1991) so far to address these design issues. For determining the number of extraction wells, simple analytical design equations based on radius of influence and effluent concentration of the contaminant have been presented by Johnson et al. (1990). The radius of influence approach was shown not to be a good design parameter for well spacing or determining the number of wells by Cho and DiGiulio (1992), who performed pneumatic pump tests and found that air pressure can dissipate quickly with distance from the well. DiGiulio (1992) presented a case where addition of wells within the radius of influence improve the efficiency of SVE. These studies suggest that effective number of wells and their placement should be based on the air flow field created near the wells. Using an air flow simulation-optimization model is therefore an attractive tool for obtaining information on these design components.

The objective of this study is to minimize the number of wells, optimize the placement of the wells and the flow rate of each well in the SVE design. This is achieved by formulating a mixed-integer programming model that takes into account both the fixed costs incurred during the well-installation and the operational costs of the wells, in the model's objective function. This model could easily be used by hydrogeologist and engineers involved in the design of SVE systems especially those who have gained experience in using MODFLOW (McDonald and Harbaugh, 1988) and (or) AIR3D (Joss and Baehr, 1995). The model is especially useful for sites that could be remediated in a few months when the installation costs of wells could be significant.

\section{Review of SVE management models}

SVE management models usually make use of air flow models and/or contaminant transport models for the unsaturated zone. The accuracy of the management models has a strong dependence on the accuracy of the flow and transport models. 
The coupling of transport and optimization models in SVE was first introduced by Davert and Yeh (1994). They modified the model developed by Rathfelder et al. (1991), to a two-dimensional numerical simulation model that captures the dynamic response of SVE system by solving for a horizontal layer. They formulated a mixed-integer nonlinear programming (MINLP) management model and employed systematic reduction method (SRM) for solving it. Sun and Yeh (1995) developed a MINLP similar to that of Davert and Yeh (1994), incorporating the two-dimensional multi-phase component transport in the unsaturated zone Rathfelder et al., 1991, but they used a K-change local search algorithm to solve it. The main difference between these two models is the optimization algorithm used to solve them.

The total remediation time of SVE was minimized by Sacks et al. (1994). They used the simulated annealing algorithm to obtain solutions for the optimal design. Sun et al. (1996) solved the MINLP problem developed taking the concentration into consideration in the two-dimensional field, using three methods: implicit enumeration, systematic reduction and local search. They solved a hypothetical problem with two wells that would maximize the total contaminant mass removal within 20 days. They compared the optimality heuristic, solution accuracy, computational efficiency, and application limitations of the three methods and concluded that local search method is most flexible and compatible for the field conditions of SVE. Welty et al. (1991, 1993) gave a qualitative analysis of the optimization of SVE and presented a Linear programming model to optimize air flow.

The model developed in this work extends the two-dimensional assumption commonly made in the management models for SVE. It makes use of a three-dimensional air flow model and extends the linear programming model to a mixed-integer programming model by including the fixed costs incurred when the costs of installing wells are taken into account. By extending the management model to three-dimensions, the effects of horizontal layers in the model and the screen length of the wells on the optimal design were studied.

\section{The Optimization model}

To develop the optimization model, a numerical air flow simulation model is required. The air flow simulation model is required to formulate constraints for the optimization model. AIR3D (Joss and Baehr, 1995) is used in this work to simulate the air flow in the unsaturated zone. In their model, the equation for air flow is linearized and solved for the air pressure squared. The resulting air flow equation is similar to the ground water flow equation and is written as (Joss and Baehr, 1995):

$$
\begin{aligned}
& \frac{\partial}{\partial x}\left(k_{x x} \frac{\partial \phi}{\partial x}\right)+\frac{\partial}{\partial y}\left(k_{y y} \frac{\partial \phi}{\partial y}\right)+\frac{\partial}{\partial z}\left(k_{z z} \frac{\partial \phi}{\partial z}\right)-W=0 \\
& \phi=P^{2}
\end{aligned}
$$

where, $x, y, z$ are the Cartesian coordinates aligned along the major axes of the air permeability tensor with diagonal components $k_{x x}, k_{y y}$ and $k_{z z}\left[\left(\mathrm{~cm}^{2}\right)\right] . \phi=$ Hydraulic 
head equivalent of pressure $\left[\left(\mathrm{g} / \mathrm{cm} \mathrm{s}^{2}\right)^{2}\right] . W=$ applied stress at a well per unit volume of the well cell (expressed as hydraulic head equivalent of pressure) $\left[\left(\mathrm{g} / \mathrm{cm} \mathrm{s}^{2}\right)^{2}\right]$. $P=$ air phase pressure $\left[\left(\mathrm{g} / \mathrm{cm} \mathrm{s}^{2}\right)\right]$.

The steady state form Eq. (1) is used since it is assumed that equilibrium of the vapor flow is achieved in a short time after the beginning of pumping and would dominate as long as constituent mole fractions of the volatile organic contaminants were high. With the assumption that advection transports the contaminants to the wells and the air flow sweeps through the bulk of the contaminated soil, Eq. (1) is solved to obtain the distribution of $\phi$ as a function of space in the modeled domain.

To obtain the coefficients of the constraint equations for the optimization model, the simulation model is solved with a unit pumping stress at a potential well location and the effects at the constraint locations recorded. The simulation model is then solved with a unit stress at another potential well location and this procedure is repeated until each potential well location has been used to run the model. The influence of each unit stress at a well on the constraint locations (response coefficient) is calculated separately using the linearized air flow model and then superposed to develop a response matrix using a matrix generator developed by the authors. A detailed description for the development of a response matrix can be found in Maddock (1972). The response matrix coefficients serve as coefficients for the constraints in the optimization model. The optimization model, when solved, gives the distribution of $\phi$ over space for any pattern of pumping. An outline of the overall procedure from data preparation to obtaining the optimal pumping rates of the wells is shown in Fig. 1.

The mixed-integer model with its associated constraints is as shown:Minimize

$$
Z=\sum_{j=i k=1}^{n} \sum_{j}^{K} c_{j}^{k} q_{j}^{k}+\beta_{j}^{k} y_{j}^{k}
$$

subject to,

$$
\begin{aligned}
& \phi_{j}^{k} \geq \phi_{j}^{*} \\
& \phi_{l 1}^{k}-\phi_{l 2}^{k} \geq \phi_{l}^{*} \\
& q_{j}^{k}-M y_{j}^{k} \leq 0 \\
& q_{j}^{k} \geq 0 \\
& y_{j}^{k}=\text { binary variable }
\end{aligned}
$$

where, $\beta_{j}^{k}=$ installation cost (fixed cost) of well $j$ in layer $k ; c_{j}^{k}=$ cost per unit pneumatic volumetric pumping rate of well $j$ in layer $k$ for the total remediation time; $q_{j}^{k}=$ pneumatic volumetric pumping rate at location $j$ in layer $k$ to be optimized $\left[\mathrm{g}^{2}\right.$ $\left.\mathrm{cm} / \mathrm{s}^{4}\right] ; n=$ the number of potential well locations from which the optimum number of wells and locations are selected; $K=$ total number of layers in the modeled domain; $\phi_{j}^{k}=$ hydraulic equivalent of pressure at location $j$, in layer $k$ due to the stress $q$ in the system; $\phi_{j}^{*}=$ bound on hydraulic equivalent of pressure at location $j$, in layer $k$; $\phi_{l 1}^{k}=$ hydraulic equivalent of pressure at location $l 1$ due to the stress in the system; 


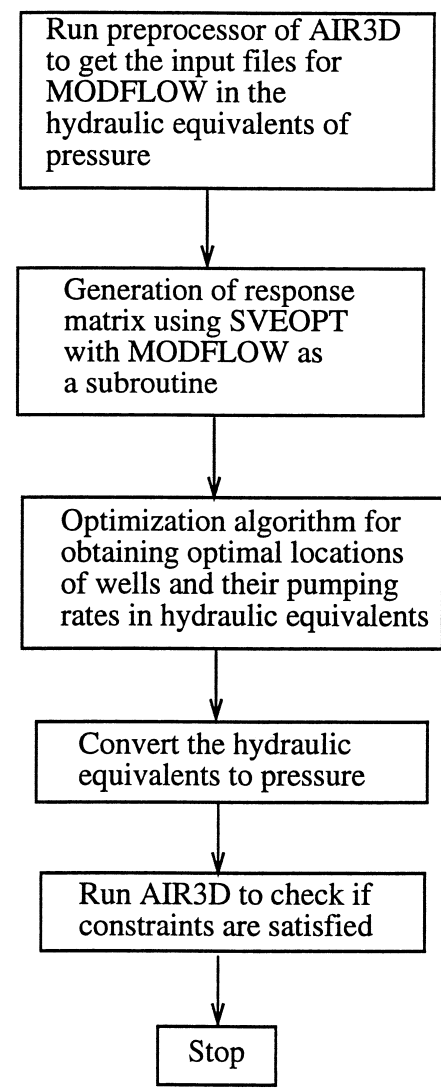

Fig. 1. Outline of the overall procedure.

$\phi_{l 2}^{k}=$ hydraulic equivalent of pressure at location $l 2$ due to the stress in the system; $\phi_{l}{ }^{*}=$ bound on the difference between the hydraulic equivalent of pressure at two locations that form a gradient constraint pair; $M=$ a large positive number that exceeds the maximum feasible value of any $q_{j}^{k}$.

The first constraint is to avoid excessive drawdown at a well. The lower bound at each potential well location was set to $0.7 \mathrm{~atm}$ in pneumatic head equivalent to avoid excessive pressure change at a well but creating enough pressure difference to allow the air to move through the bulk of the contaminated soil into the pumping wells. The second constraint is to assure that an inward pressure difference in pneumatic head equivalent greater than $\phi_{l}^{*}$ is obtained for the optimal solution. The magnitude of $\phi_{l}^{*}$ will affect the magnitude of the inward gradient created at the constraint locations. The magnitude is set such that we avoid the recharge of air to come mostly from the direction of the lateral boundaries. In the case studies presented in this work, the gradient constraints were set to achieve an inward pneumatic head difference greater than or equal to $0.001 \mathrm{~atm}$ in pneumatic head equivalent at each constraint location. 
AIR3D gives information on how much air comes through the lateral boundaries and how much is recharged from the atmosphere. A greater than $80 \%$ recharge of air from the atmosphere is considered desirable for SVE (Joss and Baehr, 1995).

As an illustration of the development of the response coefficients for a gradient constraint, suppose we have two extraction wells $q_{1}$ and $q_{2}$ at the potential well locations. Let a gradient constrained pair be located at node $l 1$ and $l 2$ in any layer $k$ on the boundary of the contaminant plume. For convenience, we drop the superscript $k$ in Eq. (3). The response constraint, after some mathematical manipulations, can be written as:

$$
\left[\frac{\mathrm{d} \phi_{l 1}}{\mathrm{~d} q_{1}}-\frac{\mathrm{d} \phi_{l 2}}{\mathrm{~d} q_{1}}\right] q_{1}+\left[\frac{\mathrm{d} \phi_{l 1}}{\mathrm{~d} q 2}-\frac{d \phi_{l 2}}{\mathrm{~d} q_{2}}\right] q_{2} \leq \phi_{l 1}-\phi_{l 2}-\alpha_{l} L
$$

where $\phi_{l 1}=\phi_{l 2}$ is the pneumatic head equivalent at the initial condition $\alpha_{l}=\phi_{l}^{*} / L$. $L$ is the distance between the two nodes that make up the control pair $\mathrm{cm}$.

A similar form of this equation is obtained for constraints on drawdown at the wells. All the constraints can be combined and written in the form shown below:

$$
\sum_{i=1}^{m} \sum_{j=1}^{n} A_{i j} q_{j} \leq b_{i}
$$

where: $A_{i j}=$ the response matrix; $b_{i}$ is the right hand side corresponding to constraint $i$; $m$ is the number of constraint.

The optimal solution for the mixed-integer programming (MIP) problem formulation greatly depends on the operational and installation (fixed) costs of the wells. The optimal solution when the model is solved with installation and without installation costs of the wells are quite different. The electric power used to pump the air (a $25 \mathrm{hp}$ pump which extracts $200 \mathrm{gpm}$ of air with US $\$ 0.10 / \mathrm{kW} \mathrm{h}$ as the cost of electric power) was taken as the operational cost and US $\$ 200 / \mathrm{m}$ as installation costs of the wells, in our case studies.

The mixed-integer programming model and the linear programming model (obtain by neglecting the fixed-charge cost) are solved using the GAMS (General Algebraic Modeling System) (Brooke et al., 1992) software. GAMS comprise of a suite of optimization algorithms including MINOS (Murtagh and Saunders, 1987) and OSL (IBM, 1991) that can solve numerous types of optimization models. In this work, MINOS was used to solve the linear programming model and OSL to solve the mixed-integer linear model. MINOS solves linear programs using the primal simplex method and OSL solves the mixed-integer program using the branch-and-bound method. Details of these algorithms can be found in the MINOS and GAMS solver manuals, respectively.

The optimal solution to the mixed-integer model gives information on the number of wells selected, their locations, and the optimal pumping rates for the wells in terms of the pneumatic volumetric flow rate $q_{i}$. The hydraulic equivalents of pressure $\phi_{i}$ at the wells selected in the optimal solution are obtained through the response coefficients and the pneumatic volumetric flow rates. 
The volumetric air flow rate $F_{\text {vol }}$ in a well is obtained from the relation (Joss and Baehr, 1995):

$$
F_{\text {vol }}=\frac{q_{i}}{2 \mu \phi_{i}^{0.5}}
$$

where, $\mu=$ dynamic air viscosity $\mathrm{g} / \mathrm{cm} \mathrm{s} ; \phi_{i}=$ hydraulic equivalent of pressure at well $i$.

\section{Model applications}

\subsection{Description of the site}

A spill is assumed to have occurred within a domain that is $(60.75 \mathrm{~m} \times 60.75 \mathrm{~m})$. The soil contamination extends over the area shown in Fig. 2 which is a subsection of

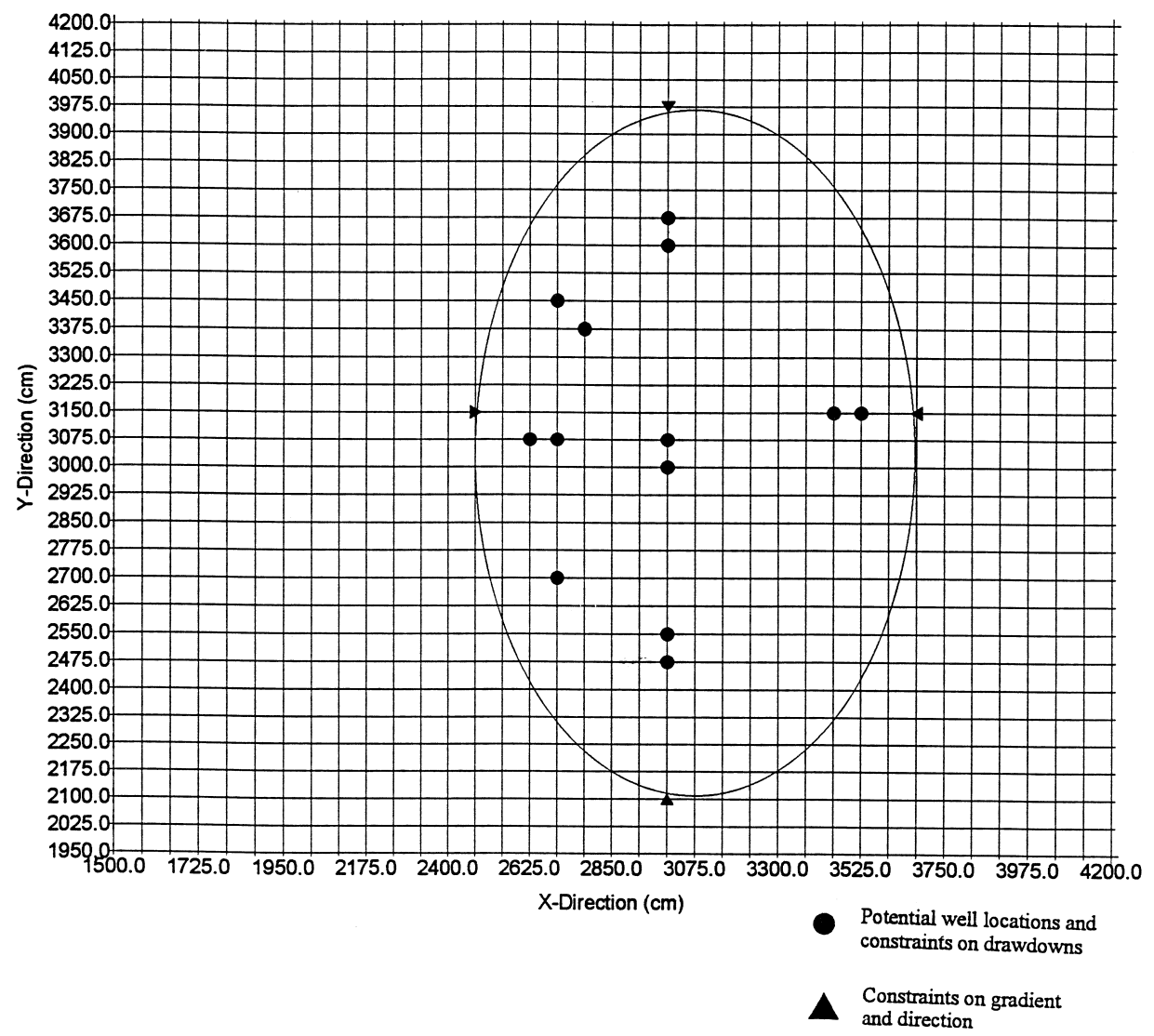

Fig. 2. Plan view of plume showing potential well locations and control locations in a layer. 
the area of the modeled domain. The full domain was discretized into 81 rows by 81 columns in the $X-Y$ (horizontal) direction. The discretization in the $Z$ direction was not constant, the number of layers were varied to test its sensitivity. Fig. 2 is a representative finite difference grid for all the layers (a maximum of six) modeled. The whole domain is not shown because it is cumbersome to show the 81 rows by 81 columns. However, it can easily be visualized from the subdomain in Fig. 2.

The site is mostly of silty sand. The model parameters are shown in Table 1 . The site is divided into two geologic units in the $Z$ direction. The depth of each geologic unit is $3.5 \mathrm{~m}$, thus, the total depth of the unsaturated zone is $7 \mathrm{~m}$. A confining unit is assumed to be present at a depth of $7 \mathrm{~m}$ throughout the domain. The water table is assumed to be below the second geologic unit at a depth such that it does not interfere with pumping. It is assumed that there is no contaminant near the water table. The compressibility of the soil due to the vacuum at the pumping well is also assumed to be negligible.

The initial and boundary conditions are specified by the preprocessor of AIR3D. The entire domain is at one atmospheric pressure, hence, at the start of the simulation, each cell in the finite difference domain is equal to the square of one atmospheric pressure.

The boundary conditions of the domain are specified in the preprocessor of AIR3D as follows: (1) an additional layer of cells is added above the uppermost model layer and a constant pressure of one atmospheric pressure squared is assigned to each cell for recharge of air to come from the atmosphere; (2) a constant head equal to one atmospheric pressure squared is assigned to the lateral boundary cells to simulate recharge from the surrounding unsaturated zone; (3) no flow is assigned to the lowest cell layer, to simulate an impervious water table or confining unit; and (4) the square of a specified constant pressure is assigned at the wells.

Table 1

Model parameters

\begin{tabular}{ll}
\hline Parameters & Values \\
\hline Type of soil & Silty sand \\
Total depth & $700 \mathrm{~cm}$ \\
Temperature & $10^{\circ} \mathrm{C}$ \\
& \\
Geologic unit 1 & $350 \mathrm{~cm}$ \\
Depth & $1.0 \times 10^{-8} \mathrm{~cm}^{2}$ \\
$X$-direction air permeability & $1.0 \times 10^{-8} \mathrm{~cm}^{2}$ \\
$Y$-direction air permeability & $1.0 \times 10^{-9} \mathrm{~cm}^{2}$ \\
$Z$-direction air permeability & 0.3 \\
Porosity & \\
Geologic unit 2 & $350 \mathrm{~cm}$ \\
Depth & $2.0 \times 10^{-8} \mathrm{~cm}^{2}$ \\
$X$-direction air permeability & $2.0 \times 10^{-8} \mathrm{~cm}^{2}$ \\
$Y$-direction air permeability & $2.0 \times 10^{-9} \mathrm{~cm}^{2}$ \\
$Z$-direction air permeability & 0.25 \\
Porosity & \\
\hline
\end{tabular}


A representative example of the potential well locations and gradient constraints in a layer is shown in Fig. 2. The optimization model has to select the best combination of wells from these locations.

\section{Simulation runs}

Different scenarios were tested by increasing and (or) decreasing either one of the following and keeping the others as constant.

- number of layers

- number of potential wells

- screen length of the wells

- number of constraints

These scenarios are summarized in Table 2. A pneumatic head constraint is placed at each potential well location. It should be noted that two geological units were modeled and the number of layers shown in each case studied were distributed equally between the two geological units. The layer numbering increases in the negative $Z$ direction and the depth of each layer in each case study is the same.

Table 2

Cases studied

\begin{tabular}{lllll}
\hline Case & $\begin{array}{l}\text { Number of potential } \\
\text { well locations }\end{array}$ & $\begin{array}{l}\text { Layer wells } \\
\text { are located }\end{array}$ & $\begin{array}{l}\text { Number of gradient } \\
\text { constraint pairs }\end{array}$ & $\begin{array}{l}\text { Layer gradient constraints } \\
\text { are located }\end{array}$ \\
\hline Case 1 (2 layers) & 5 & 2 & 4 & 2 \\
Case 2 (4 layers) & 5 & 4 & 4 & 4 \\
Case 2a (4 layers) & 5 & 3 & 4 & 3 \\
Case 2b (4 layers) & 5 & 4 & 4 & 2 \\
& 5 & 2 & 4 & 3 \\
& 5 & 3 & 4 & 4 \\
Case 2c (4 layers) & 9 & 4 & 4 & 4 \\
& 9 & 3 & 4 & 3 \\
Case 2d (4 layers) & 13 & 4 & 4 & 4 \\
& 13 & 3 & 4 & 3 \\
Case 2e (4 layers) & 5 & 4 & 4 & 4 \\
& 5 & 3 & 8 & 3 \\
Case 2f (4 layers) & 5 & 4 & 8 & 4 \\
Case 3 (6 layers) & 5 & 4 & 4 & 3 \\
Case 3a (6 layers) & 5 & & 4 & 6 \\
& 5 & 6 & 4 & 5 \\
Case 3b (6 layers) & 5 & 5 & 4 & 6 \\
& 5 & 6 & 4 & 5 \\
Case 3c (6 layers) & 5 & 4 & 4 & 6 \\
& 5 & 5 & 4 & 4 \\
& & 6 & 4 & 6 \\
\hline
\end{tabular}




\section{Results and discussion}

The results from the optimization model when the cost of installing the wells are neglected are shown in Table 3. Similarly, Table 4 shows results when the MIP model is solved. Table 5 shows all the selected well locations and pumping rates for an example scenario (case 2d) for the LP and MIP model. In general, it is observed from the tables that the number of wells selected in the MIP optimal solution is less than that in the LP solution but the volumetric flow rate is greater in the MIP problem. This is a result of the significance of the installation cost for the 4-month remediation time specified in these case studies. To minimize the total cost of remediation, the effect of the installation costs is to reduce the total number of wells selected. The selection of less wells resulted in higher pumping rates to satisfy the constraints of the system. It is also observed that in the MIP case, the optimization model selected more wells in the top layers when compared to the LP case. This is because the installation costs increase with increase in depth.

The general trend in the variation of the optimization results for the MIP and LP for the case studies is quite similar. The discussion of the different scenarios tested in the simulation runs follows.

Table 3

The result of the linear programming problem

\begin{tabular}{|c|c|c|c|c|c|}
\hline Case & $\begin{array}{l}\text { Number of } \\
\text { potential } \\
\text { well } \\
\text { locations }\end{array}$ & $\begin{array}{l}\text { Layer } \\
\text { wells } \\
\text { are } \\
\text { located }\end{array}$ & $\begin{array}{l}\text { Number } \\
\text { of wells } \\
\text { selected }\end{array}$ & $\begin{array}{l}\text { Volumetric } \\
\text { air flow } \\
\text { rate per } \\
\text { layer } \\
\left(\mathrm{cm}^{3} / \mathrm{s}\right)\end{array}$ & $\begin{array}{l}\text { Total volumetric air } \\
\text { flow rate }\left(\mathrm{cm}^{3} / \mathrm{s}\right)\end{array}$ \\
\hline Case 1 (2 layers) & 5 & 2 & 3 & 10,676 & 10,676 \\
\hline Case 2 (4 layers) & 5 & 4 & 3 & 8662 & 8,662 \\
\hline \multirow[t]{2}{*}{ Case 2a (4 layers) } & 5 & 3 & 3 & 5894 & 12,352 \\
\hline & 5 & 4 & 2 & 6458 & \\
\hline \multirow[t]{3}{*}{ Case $2 b$ (4 layers) } & 5 & 2 & 3 & 5068 & 15,183 \\
\hline & 5 & 3 & 3 & 4816 & \\
\hline & 5 & 4 & 3 & 5299 & \\
\hline \multirow[t]{2}{*}{ Case 2c (4 layers) } & 9 & 3 & 4 & 3641 & 7757 \\
\hline & 9 & 4 & 4 & 4116 & \\
\hline \multirow[t]{2}{*}{ Case $2 d$ (4 layers) } & 13 & 3 & 4 & 3641 & 7757 \\
\hline & 13 & 4 & 4 & 4116 & \\
\hline \multirow[t]{2}{*}{ Case 2e (4 layers) } & 5 & 3 & 3 & 3785 & 18,326 \\
\hline & 5 & 4 & 2 & 14,541 & \\
\hline Case 2f (4 layers) & 5 & 4 & 3 & 47,713 & 47,713 \\
\hline Case 3 (6 layers) & 5 & 6 & 3 & 7813 & 7813 \\
\hline \multirow[t]{2}{*}{ Case $3 a$ (6 layers) } & 5 & 5 & 3 & 6232 & 10,670 \\
\hline & 5 & 6 & 2 & 4438 & \\
\hline \multirow[t]{3}{*}{ Case 3b (6 layers) } & 5 & 4 & 2 & 1973 & 13,864 \\
\hline & 5 & 5 & 2 & 9812 & \\
\hline & 5 & 6 & 2 & 2079 & \\
\hline Case 3c (6 layers) & 5 & 6 & 5 & 43,912 & 43,912 \\
\hline
\end{tabular}


Table 4

The results of the mixed-integer programming problem

\begin{tabular}{|c|c|c|c|c|c|}
\hline Case & $\begin{array}{l}\text { Number of } \\
\text { potential } \\
\text { well } \\
\text { locations }\end{array}$ & $\begin{array}{l}\text { Layer } \\
\text { wells } \\
\text { are } \\
\text { located }\end{array}$ & $\begin{array}{l}\text { Number } \\
\text { of wells } \\
\text { selected }\end{array}$ & $\begin{array}{l}\text { Volumetric } \\
\text { air flow } \\
\text { rate per } \\
\text { layer } \\
\left(\mathrm{cm}^{3} / \mathrm{s}\right)\end{array}$ & $\begin{array}{l}\text { Total volumetric air } \\
\text { flow rate }\left(\mathrm{cm}^{3} / \mathrm{s}\right)\end{array}$ \\
\hline Case 1 (2 layers) & 5 & 2 & 2 & 13,965 & 13,965 \\
\hline Case 2 (4 layers) & 5 & 4 & 1 & 12,860 & 12,860 \\
\hline \multirow[t]{2}{*}{ Case 2a (4 layers) } & 5 & 3 & 3 & 6080 & 13,566 \\
\hline & 5 & 4 & 1 & 7486 & \\
\hline \multirow[t]{3}{*}{ Case $2 \mathrm{~b}$ (4 layers) } & 5 & 2 & 2 & 4967 & 17,679 \\
\hline & 5 & 3 & 1 & 6885 & \\
\hline & 5 & 4 & 1 & 5827 & \\
\hline \multirow[t]{2}{*}{ Case 2c (4 layers) } & 9 & 3 & 3 & 3814 & 12,747 \\
\hline & 9 & 4 & 1 & 8933 & \\
\hline \multirow[t]{2}{*}{ Case $2 \mathrm{~d}$ (4 layers) } & 13 & 3 & 3 & 3814 & 12,747 \\
\hline & 13 & 4 & 1 & 8933 & \\
\hline \multirow[t]{2}{*}{ Case 2e (4 layers) } & 5 & 3 & 1 & 2250 & 35,037 \\
\hline & 5 & 4 & 1 & 32,787 & \\
\hline Case $2 \mathrm{f}$ (4 layers) & 5 & 4 & 3 & 47,763 & 47,763 \\
\hline Case 3 (6 layers) & 5 & 6 & 1 & 14,234 & 14,234 \\
\hline \multirow[t]{2}{*}{ Case $3 a$ (6 layers) } & 5 & 5 & 3 & 5610 & 11,157 \\
\hline & 5 & 6 & 1 & 5547 & \\
\hline \multirow[t]{3}{*}{ Case $3 b$ (6 layers) } & 5 & 4 & 0 & 0 & 32,675 \\
\hline & 5 & 5 & 1 & 875 & \\
\hline & 5 & 6 & 1 & 31,800 & \\
\hline Case 3c (6 layers) & 5 & 6 & 3 & 47,449 & 47,449 \\
\hline
\end{tabular}

Table 5

Well locations and pumping rates for case $2 \mathrm{~d}$

\begin{tabular}{|c|c|c|c|c|c|}
\hline $\begin{array}{l}\text { Case } \\
2 \mathrm{~d}\end{array}$ & $\begin{array}{l}x \\
\text { Coordinate } \\
\text { of wells } \\
\text { selected } \\
(\mathrm{cm})\end{array}$ & $\begin{array}{l}y \\
\text { Coordinate } \\
\text { of wells } \\
\text { selected } \\
(\mathrm{cm})\end{array}$ & $\begin{array}{l}z \\
\text { Coordinate } \\
\text { of wells } \\
\text { selected } \\
\text { (Layer) }\end{array}$ & $\begin{array}{l}\text { Volumetric } \\
\text { flow rate } \\
\left(\mathrm{cm}^{3} / \mathrm{s}\right)\end{array}$ & $\begin{array}{l}\text { Total } \\
\text { volumetric } \\
\text { flow rate } \\
\left(\mathrm{cm}^{3} / \mathrm{s}\right)\end{array}$ \\
\hline \multirow[t]{8}{*}{ Linear programming model } & 2625 & 3075 & 3 & 548 & \\
\hline & 3000 & 3675 & 3 & 1116 & \\
\hline & 3525 & 3150 & 3 & 520 & \\
\hline & 3000 & 2475 & 3 & 1457 & 7757 \\
\hline & 2700 & 3075 & 4 & 646 & \\
\hline & 3000 & 3600 & 4 & 1268 & \\
\hline & 3450 & 3150 & 4 & 543 & \\
\hline & 3000 & 2550 & 4 & 1659 & \\
\hline \multirow[t]{4}{*}{ Mixed-integer programming model } & 3000 & 3000 & 3 & 2486 & \\
\hline & 3000 & 3075 & 4 & 8933 & 12,747 \\
\hline & 3000 & 3675 & 3 & 588 & \\
\hline & 3000 & 2475 & 3 & 740 & \\
\hline
\end{tabular}


When the number of well locations in the same layer is increased keeping the constraints and the screen length constant (cases $2 \mathrm{a}, 2 \mathrm{c}$ and $2 \mathrm{~d}$ ), the total volumetric flow rate of the wells selected by the optimization algorithm decreased or remained the same. Increasing the potential number of well locations gives the algorithm a larger number of wells to choose from with the possibility of improving on the best combination of wells to minimize the objective function. This was observed in cases $2 \mathrm{a}$ and $2 \mathrm{c}$. However, when the number of wells was further increased (as in case $2 \mathrm{~d}$ ), the optimal solution remained the same. This may be due to the model having reached the best optimal solution or it may be that the increased number of wells were a poor choice. The simulation was not done, further increasing the number of wells to test if the best optimal solution was reached due to the large computational time required for each run. Case 2d, for example, took about $8 \mathrm{~h}$ on a UNIX SUN Sparcstation 2 for the development of the response matrix. Once the response matrix was developed, it took a few seconds to 2 min to obtain an optimal solution from GAMS.

Increasing the number of constraints by introducing the additional constraints in a layer where there is no well had a significant impact on the optimal solution. In case $2 \mathrm{f}$, wells were located in layer 4 and gradient constraints were located in layer 4 and 3 . A scenario of this nature where constraints are located in a layer where there is no well, resulted in a much higher pumping rate than if wells were in each layer. Case $2 \mathrm{a}$ is similar to case $2 \mathrm{f}$ with additional wells placed in layer 3 in case $2 \mathrm{a}$. The volumetric flow rate in case $2 \mathrm{a}$ is much less than in case $2 \mathrm{f}$ because less pumping is required to satisfy the constraints in layer 3 when wells are located in this layer. A similar situation is demonstrated in cases 3 and $3 \mathrm{c}$. This information reveals that if the contaminant plume extends over two or three layers, for example, the screen length should extend over these layers to minimize the amount of pumping required. Making the screen length too short would result in excessive pumping.

The number of constraints on the system also influences the optimal solution. Increasing the number of constraints around the periphery of the contaminant plume in the same layer (keeping the well locations and the screen length constant) resulted in a better constrained problem. Adding more constraints resulted in an increase in the total volumetric flow rate because of the stricter conditions imposed due to the increase in the number of constraints. This is observed in cases $2 \mathrm{a}$ and $2 \mathrm{e}$ where the well location and the screen lengths are the same. The number of constraints in case $2 \mathrm{e}$ is increased and thus, the volumetric flow rate of case $2 \mathrm{e}$ is greater than that of case $2 \mathrm{a}$. For effective design, the number of constraints should be as large as possible to assure that the air sweeps through the whole plume. However, the size of the optimization problem increases with the number of constraints and over-constraining the problem could lead to an infeasible solution.

If the screen length is decreased with the same number of potential well locations and the same constraints, one may expect the total volumetric flow would increase to satisfy the conditions. It should be noted that the total volumetric flow depends on the number of wells selected and their locations. There is a decrease in the screen length from case 1 to case $2 \mathrm{f}$ to case $3 \mathrm{c}$, but the trend observed in the total volumetric flow is not increasing in order. This was due to the variation in the number of wells selected and their locations in each case. If the wells selected for all the screen lengths are the same (at 
same locations), then the total volumetric flow will increase with the decrease in the screen length.

The number of layers had an effect on the optimal solution. For the LP problem, as the number of layers within geologic unit 2 was increased (cases 1, 2a and 3b), the total volumetric flow rate increased. This was due mainly to the additional constraints and wells added for each additional layer introduced. For the mixed-integer case, the trend depends on the costs associated with operating the wells and the installation cost of the wells.

\section{Conclusions}

The effectiveness of SVE is strongly affected by the number of extraction wells, the location and the pumping rates of these wells. However, there is limited guidance in the literature for determining the number, locations and pumping rates of wells for remediating the unsaturated zone by SVE. The model presented should therefore be of wide interest to those interested in the design of SVE systems due to lack of general design and operation criteria and the site specific nature of SVE systems. As SVE is generally very effective on homogeneous soils with high permeability, low moisture content and low organic carbon content, the MIP model presented in this paper, would be most useful under these conditions. However, if there are limitations on mass transfer due to low volatility rate of the contaminant and/or diffusion controlled transport, then an optimization model that takes into account contaminant distribution through space and time would be most useful. A three-dimensional contaminant transport would then be required to address the issues discussed in this paper. Optimization models of this nature that take into account the three-dimensionality of the unsaturated zone are yet to appear in the literature.

In this work, we have shown that if in addition to an SVE model, we incorporate optimization procedures, the analytical capabilities of the simulation model is enhanced for the SVE design decision-making process. So far, there remains the absence of published reports describing the implementation of combined simulation-optimization models for SVE. This is not to say that these models cannot be used to aid 'real-world' decision-making. SVE simulation-optimization models are fairly recent and gradually gaining acceptance as a tool to provide guidance in the design of 'real world' SVE systems.

\section{Acknowledgements}

The authors wish to express their gratitude to The Environmental Research Institute at The University of Connecticut for providing partial financial support for this research. We also thank Arthur Baehr of the USGS for providing us with the AIR3D software used in this research. 


\section{References}

Brooke, A., Kendrick, D., Meeraus, A., 1992. GAMS, A Users Guide. Release 2.25, Boyd \& Fraser, Danvers, MA 01923.

Cho, J.S., DiGiulio, D.C., 1992. Pneumatic pumping test for soil vacuum extraction. Environ. Prog. 11 (3), $228-333$.

Davert, M.W., Yeh, W. W-G., 1994. Optimization of the Design and Operation of Soil Vapor Extraction Systems. Proceedings of 21st Annual Conference of the Water Resources Planning and Management Div. Am. Soc. of Civ. Eng., pp. 181-184.

DiGiulio, D.C., 1992. Ground Water Issue-Evaluation of Soil Venting, US, EPA/540/S-92/004.

IBM, 1991. Optimization Subroutine Library, Guide and Reference, Release 2.

Johnson, P.C., Stanley, C.C., Kemblowski, M.W., Byers, D.L., J. Colthart, D., 1990. A Practical Approach to the Design Operation and Monitoring of In-Situ Soil-Venting Systems. GWMR, pp. 159-178.

Joss, C.J., Baehr, A.L., 1995. Documentation of AIR3D, An Adaption of the Groundwater Flow Code MODFLOW to Simulate Three-Dimensional Air Flow in the Unsaturated Zone. USGS, Open-File, pp. 94-533.

Maddock, T. III, 1972. Algebraic technological function from a simulation model. Water Resour. Res. 8 (1), $129-134$.

McDonald, M.G., Harbaugh, A.W., 1988. A Modular Three-Dimensional Finite-Difference Ground-Water Flow Model. MODFLOW, US Geological Survey Open-File Report, pp. 83-875.

Murtagh, M., Saunders, M.A., 1987. MINOS 5.1, User's Guide. Technical Report SOL 83-20R.

Rathfelder, K., Yeh, W.W.-G., Mackay, D., 1991. Mathematical simulation of soil vapor extraction systems: model development and numerical examples. J. Contam. Hydrol. 8, 263-297.

Sacks, R.L., Dougherty, D.E., Guarnaccia, J.F., 1994. The Design of Optimal Soil Vapor Extraction Remediation Systems Using Simulated Annealing. Proceedings of 1994 Groundwater Modeling Conference, Int. Groundwater Modeling Cent., Fort Collins, CO, pp. 343-350.

Sun, Y.H., Yeh, W.W.-G., 1995. Mixed-Integer Nonlinear Optimization of Soil Vapor Extraction Systems. Proceedings of 22nd Annual Conference of Water Resources Planning and Management Div. Am. Soc. Civ. Eng., New York, pp. 883-886.

Sun, Y.H., Davert, M.W., Yeh, W.W.-G., 1996. Soil vapor extraction system design by combinatorial optimization. Water Resour. Res. 32 (6), 1863-1873.

Welty, C., Baehr, A.L., Joss C.J., Dillow, J.J.A., 1991. Use of mathematical programming coupled with a transport model to optimize the design of vapor-extraction systems. In: Mallard, G.E., Aronson, D.A. (Eds.), US Geological Survey Toxic Substances Hydrology Program. Proceedings of the Technical Meeting, Monterey, CA, March 11-15. US Geological Survey Water Resources Investigations Report 91-4034, pp. 276-279.

Welty, C., Joss, C.J., Baehr, A.L., 1993. A three-dimensional air flow model coupled with a mathematical programming model to optimize vapor extraction design. In: Morganwalp, D.W., Aronson, D.A. (Eds.), US Geological Survey Toxic Substances Hydrology Program. Proceedings of the Technical Meeting, Colorado Springs, CO, September 20-24. US Geological Survey Water Resources Investigations Report 94-4015. 